\title{
AS INTERAÇÕES ENTRE AS PEQUENAS E MEDIAS EMPRESAS BRASILEIRAS E AS INSTITUIÇÕES DE CIÊNCIA E TECNOLOGIA: NOTAS INTRODUTORIAS SOBRE AS CARACTERÍSTICAS DAS FIRMAS INTERATIVAS E DOS SEUS RELACIONAMENTOS UNIVERSIDADE-EMPRESA
}

\author{
Vanessa Parreiras Oliveira \\ Doutoranda em Ciências Econômicas \\ Instituto de Economia - IE/UNICAMP
}

\begin{abstract}
Resumo
O principal objetivo deste trabalho é examinar algumas características estruturais das pequenas e médias (PMEs) brasileiras que cooperaram com instituições de ciência e tecnologia (ICTs), que abrangem as universidades e os institutos públicos de pesquisa (IPPs), com vistas ao desenvolvimento de suas atividades inovativas, bem como de seus relacionamentos cooperativos. Para cumprir com este propósito são apresentados alguns resultados preliminares e descritivos da base de dados do Censo 2010 do Diretório de Grupos de Pesquisa do Conselho Nacional de Desenvolvimento Científico e Tecnológico (DGP/CNPq). Esses dados mostram algumas características estruturais principais e preliminares das PMEs interativas e o papel desempenhado pela universidade na criação e difusão do conhecimento entre estas empresas no país.
\end{abstract}

\begin{abstract}
The main aim of this paper is to exam some firm characteristics of the Brazilian small and medium-sized enterprises (SMEs) that cooperated with science and technology institutions (comprising universitites and public research institutes) in Brazil in their innovative activities, as well as their cooperative relationships. To do that, it is presented some preliminary and descriptive results from the 2010 database from the Brazilian Research Council (CNPq), collected at the CNPq Directory of Research Groups in Brazilian universities. These data show some main, and preliminary, characteristics of the firms thar cooperate with universities and public research institutes and the role played by the university in the creation and diffusion of knowledge among these firms in the country.
\end{abstract}

Palavras-chave: 1) pequenas e médias empresas; 2) características das firmas interativas; 3) tipos de relacionamento U-E; 4) e sistema nacional de inovação

Key Words: 1) small and medium-sized enterprises (SMEs); 2) characteristics of interactive firms; 3) types of university-industry relationshisps; 4) national systems of innovation

Área ABEIN 6

Classificação JEL: O30; 039 


\section{INTRODUÇÃO}

A literatura sobre os sistemas nacionais de inovação (National Systems of Innovation NSIs) atribui importância decisiva à interação entre a produção cientifica e tecnológica. Esta elaboração teórica demonstra que as universidades e os institutos públicos de pesquisa (IPPs) envolvidos na produção de ciência básica e aplicada são partes importantes do NSI, agindo de um modo que os torna complementares às atividades inovativas desenvolvidas pela indústria.

As universidades desempenham um papel central na criação e na difusão do conhecimento através de funções tradicionais, como o ensino e a pesquisa básica, constituindo elementos-chave dentro do NSI. Desta forma, criam e renovam o estoque de conhecimento existente nos países onde atuam, desempenhando um importante papel no desenvolvimento tecnológico, seja na formação e treinamento de engenheiros e cientistas industriais, seja como fonte de resultados de pesquisa e técnicas de considerável relevância para o avanço técnico na indústria (NELSON e ROSENBERG, 1993). Adicionalmente, as universidades desenvolvem e provêm novos conhecimentos que influenciam o setor produtivo por meio da pesquisa disseminada em publicações, projetos de pesquisa cooperativos ou consultoria (SCHARTINGER et al, 2001; 2002). No NSI, essas instituições apresentam um papel de produtores e difusores de conhecimento científico, e não apenas de formação e qualificação dos recursos humanos (COHEN et al, 2002).

A literatura sugere a existência de funções específicas das universidades em países em desenvolvimento. Conforme Albuquerque (1999), a infraestrutura científica pode atuar nos países periféricos como uma "antena” na identificação das oportunidades tecnológicas, conectando o NSI aos fluxos científicos e tecnológicos internacionais. Ademais, Rapini et al. (2009) e Albuquerque et al. (2005) sugeriram que, além das funções tradicionais (fonte de informação, fornecimento de mão-de-obra especializada, treinamento, etc), as universidades em NSIs imaturos ${ }^{1}$ podem desempenhar um papel dual, ou seja, elas substituem e complementam os investimentos em $P \& D$ relativamente mais fracos das firmas. Desse modo, a pesquisa acadêmica auxilia as firmas a superar as restrições de tamanho e aumentar a flexibilidade (RAPINI et al., 2009).

A literatura que aborda especificamente a inovação em PMEs identifica que elas encontram vários problemas e obstáculos relacionados aos seus escassos recursos (ROTHWELL, 1989; FREEL, 2000). Segundo Freel (2000), as pequenas firmas se confrontam com restrições associadas à falta de trabalho tecnicamente qualificado; uso limitado de informação e expertise externas; dificuldade em atrair/assegurar financiamento e incapacidade relacionada para disseminar o risco; inadequação da gestão original para além da prescrição inicial; e elevado custo da conformidade regulatória. Em essência, os constrangimentos à inovação nesse segmento de firmas relacionam-se aos seus escassos recursos (ROTHWELL, 1989; FREEL, 2000; HEWITT-DUNDAS, 2006).

Ainda segundo a literatura, as vantagens inovativas das grandes firmas estão, essencialmente, associadas aos seus maiores recursos financeiros e tecnológicos, que se traduzem em vantagens materiais; já as vantagens das pequenas empresas são aquelas relacionadas ao dinamismo empreendedor, à flexibilidade interna e à capacidade de resposta às mudanças circunstanciais, isto é, são vantagens comportamentais (ROTHWELL, 1989). A força do pequeno negócio reside na maior motivação, no melhor levantamento da totalidade de um projeto, no conhecimento tácito em habilidades únicas, na comunicação mais informal ao longo de linhas mais curtas, na menor burocracia e na maior proximidade com o mercado e com a própria produção (NOTEBOOM, 1994). Seria esperado, portanto, que as pequenas firmas, dadas as suas habilidades, estivessem melhor posicionadas para superar os constrangimentos em um período através da reconfiguração de seus recursos internos, como um resultado de sua maior flexibilidade organizacional (HEWITT-DUNDAS, 2006).

As interações universidade-empresa (U-E) têm apresentado uma frequência crescente no debate acadêmico brasileiro, evidenciada pelo elevado interesse pelo tema. Todavia, embora seja crescente o reconhecimento do papel desempenhado pelas micro, pequenas e médias empresas na promoção do crescimento econômico e na geração de emprego e renda (NOGUEIRA e OLIVEIRA, 2009; SANTOS et

\footnotetext{
${ }^{1}$ Albuquerque (1999) sugeriu uma tipologia que diferencia os NSIs de acordo com o seu nível de desenvolvimento: maduro nos países desenvolvidos; imaturos em países em um nível intermediário, como os países latino-americanos, África do Sul e Índia; e NSIs “inexistentes ou rudimentares” nos países menos desenvolvidos.
} 
al., 2012) e de sua contribuição considerável ao processo de inovação e à mudança técnica especificamente (FREEL, 2000), há uma lacuna na investigação empírica de como as características individuais das PMEs influenciam o seu envolvimento com a interação U-E e dos fatores que influenciam o(s) modo(s) como estas empresas exploram o conhecimento de universidades e IPPs em suas atividades inovativas.

Nessa linha, este trabalho procura trazer novos elementos para essa discussão, a partir do exame de algumas características estruturais das PMEs brasileiras que cooperaram com instituições de ciência e tecnologia (ICTs), que abrangem as universidades e os IPPs, com vistas ao desenvolvimento de suas atividades inovativas, bem como de seus relacionamentos cooperativos. Deste modo, este artigo procura contribuir para preencher a lacuna sobre os padrões de interação entre PMEs e universidades e IPPs no país, trazendo evidências sobre as características estruturais das PMEs que são conducentes à interação UE. bem como dos seus relacionamentos cooperativos.

Para cumprir com este propósito, são apresentados alguns resultados preliminares e descritivos da base de dados do Censo 2010 do Diretório de Grupos de Pesquisa do Conselho Nacional de Desenvolvimento Científico e Tecnológico (DGP/CNPq). Estes resultados descritivos e preliminares são insuficientes para se apresentar e discutir um padrão de interações entre PMEs e universidades e IPPs no Brasil, mas eles podem mostrar algumas características principais e preliminares das firmas que se engajam na interação U-E e de seus relacionamentos cooperativos.

O texto está organizado em cinco seções, além desta introdução. A segunda seção apresenta uma revisão da literatura empírica que aborda a interação U-E de PMEs, com foco nos determinantes dos relacionamentos cooperativos. A terceira seção apresenta uma contextualização das atividades inovativas de PMEs, elaborada com base nos dados da Pesquisa de Inovação do Instituto Nacional de Geografia e Estatística (PINTEC/IBGE). A metodologia, apresentada na quarta seção, explica a montagem da base da qual foram extraídos os dados utilizados e as variáveis utilizadas para se construir um mapa preliminar das interações U-E de PMEs no Brasil. A quinta seção examina algumas características estruturais das PMEs brasileiras que cooperaram ICTs e de seus relacionamentos cooperativos, a partir dos resultados obtidos por meio da análise descritiva dos dados do DGP/CNPq. Finalmente, na última seção são feitas as considerações finais acerca do trabalho.

\section{OS DETERMINANTSE (DRIVERS) DAS INTERAÇÕES UNIVERSIDADE-EMPRESA DE PEQUENAS E MÉDIAS EMPRESAS}

A relação entre a universidade e a indústria é um fenômeno complexo e heterogêneo. A intensidade dos vínculos varia entre firmas, setores e países (FONTANA et al., 2003; CARDAMONE e PUPO, 2015). Ambos os agentes diferem em termos dos incentivos que eles têm para colaborar e dos comportamentos que eles adotam durante o processo de colaboração (DE FUENTES e DUTRENIT, 2012).

A revisão da literatura empírica indica que são diversas as variáveis que presumivelmente influenciam a propensão das firmas a cooperar com universidades e IPPs. Segundo Schartinger et al. (2002), as interações U-E são muito influenciadas por um grande conjunto de diferentes fatores que produzem um complexo padrão de interações. Segundo os autores, uma variedade de fatores efetivamente importa nas diferenças na intensidade dos fluxos de conhecimento entre a universidade e a indústria. Entre eles, há fatores específicos à firma (relacionados a firmas pequenas/grandes, uni/multilocais, em rede/não estruturadas em rede) e fatores específicos à indústria que afetam o tipo e a quantidade de conhecimento requerido, como o conhecimento é concebido, como a aquisição de conhecimento é organizada, quem participa na aquisição de conhecimento, etc.

O papel do tamanho da firma na influência sobre a probabilidade das firmas cooperarem com os centros de pesquisa pública é um dos princípios básicos da literatura sobre as relações U-E (CARDAMONE e PUPO, 2015). Alguns estudos da década de 1990 encontraram que as pequenas firmas se beneficiam mais dos spillovers da pesquisa baseada em universidades dos que as grandes firmas, que se apoiam mais em sua própria P\&D (LINK e REES, 1990; ACS et al., 1994a, 1994b; AUDRETSCH e VIVARELLI, 1994). 
Cardamone e Pupo (2015) salientaram que o efeito do tamanho da firma na influência sobre a probabilidade das firmas cooperarem com centros de pesquisa pública é a priori pouco claro. Por um lado, as grandes firmas são capazes de dedicar maiores recursos e tempo à construção de vínculos com as universidades. Por outro lado, as empresas menores possuem menos recursos internos e necessitam mais de conhecimento externo, o que significa mais parceiros cooperativos.

Muitos estudos que investigam os fatores determinantes (drivers) da cooperação U-E, baseados em dados de países desenvolvidos, revelam que o tamanho da firma é positivamente relacionado à probabilidade das firmas utilizarem o conhecimento de universidades e a cooperarem com elas (por exemplo, COHEN et al., 2002 e SANTORO e CHAKRABARTI, 2002, para os Estados Unidos; MOHNEN e HOAREAU, 2003, para Alemanha, França, Irlanda e Espanha; FONTANA et al., 2003, para Dinamarca, França, Alemanha, Grécia, Itália, Holanda e Reino Unido; LAURSEN e SALTER, 2004, para o Reino Unido; HANEL e ST-PIERRE, 2006, para o Canadá; SCHARTINGER et al., 2001 para a Áustria; e CARDAMONE e PUPO, 2015, para Alemanha, Itália, Espanha e Reino Unido). Os resultados destes trabalhos são consistentes com a hipótese de que a capacidade das firmas utilizarem a pesquisa universitária aumenta com o tamanho da organização.

Segundo Fontana et al. (2003), a influência que o tamanho da firma pode exercer sobre a colaboração em $P \& D$ se deve ao fato de que as grandes firmas têm mais recursos que podem auxiliá-las a estabelecer seus relacionamentos com organizações públicas de pesquisa, ao passo em que quanto menor a firma, menos recursos estarão disponíveis para o desenvolvimento de múltiplos relacionamentos.

Laursen e Salter (2004) acrescentaram que as maiores firmas são mais propensas a possuir a capacidade para explorar fontes externas de conhecimento e para gerir interações com universidades. Isso por que as grandes firmas são capazes de dedicar maiores recursos e tempo à construção de vínculos com universidades do que as pequenas firmas, que podem operar em um ambiente com recursos mais limitados. Segundo os autores, as grandes firmas são também mais prováveis de empregar um staff com treinamento profissional em ciência e engenharia. Com tal background profissional, esses empregados são capazes de extrair de suas relações com universidades para dar suporte ao trabalho na organização.

Da mesma forma, segundo Mohnen e Hoareau (2003), esperar-se-ia que as maiores firmas tenham a quantidade mínima de pessoal qualificado, esforço de pesquisa e conexões globais para considerar útil estabelecer contatos com universidades e laboratórios governamentais. Ademais, as grandes firmas são mais propensas a deter os meios para atrair pesquisadores competentes, a ter um programa de P\&D contínuo e a reservar um orçamento à parte para colaborações com a ciência básica para derivar os seus benefícios em uma perspectiva de longo prazo.

Segundo Cardamome e Pupo (2015), um dos tópicos recorrentes na cooperação em P\&D é o papel da idade da firma na influência da propensão à cooperação. Firmas jovens dependem de inovações tecnológicas e do progresso científico e são mais inclinadas que outras a se engajarem em interações com universidades. Adicionalmente, pela criação de novo conhecimento e treinamento de solucionadores de problemas, as universidades dão suporte à formação de start-ups. A questão, segundo os autores, é mais controversa para as firmas mais velhas. Por um lado, firmas mais velhas podem ter estabelecido um conjunto de ligações com universidades ao longo do tempo e, então, possuir mais experiência em cooperação, que pode conduzir a uma maior propensão a interagir. Por outro lado, pode-se esperar que firmas mais velhas sejam menos dependentes de conhecimento externo gerado em universidades, posto que foram capazes de acumular um estoque de conhecimento interno à firma e, desse modo, incorporar um grande número de campos de conhecimento. A literatura empírica difere em relação à isso.

Cohen et al. (2002) usaram dados do Carnegie Mellon Survey da P\&D Industrial e consideraram quais papéis os diferentes tipos de firmas (ex. grandes versus pequenas e start-ups versus firmas estabelecidas) desempenham no estabelecimento da ponte entre a pesquisa pública e a P\&D industrial. Os autores salientam que, em contraste a trabalhos prévios (por exemplo, ACS et al., 1994), seus resultados mostram robustamente que as grandes firmas apresentam uma maior probabilidade de se beneficiar da pesquisa acadêmica. Apesar de as pequenas firmas em geral explorarem menos a pesquisa pública, as empresas start-ups parecem utilizá-las mais, especialmente na indústria farmacêutica Os autores notaram que as start-ups usam a pesquisa pública em um maior percentual de seus projetos de P\&D do que as outras firmas e são mais propensas a usar a pesquisa pública para a conclusão de projetos existentes; 
contudo, elas não confiam claramente mais na pesquisa pública como uma fonte de ideias para novos projetos do que as outras firmas. A esse respeito, os autores sugeriram que algumas start-ups são originadas em universidades e, então, têm fortes laços pré-existentes ou talvez sejam spinoffs de grandes firmas e, consequentemente, se beneficiem dos laços mais fortes que existem entre as firmas maiores e as instituições públicas de pesquisa.

Laursen e Salter (2004) notaram que as empresas start-ups são frequentemente vistas como um veículo central para transferir a pesquisa universitária em inovação comercial, especialmente nos setores baseados em ciência, tais como biotecnologia e sofware. Pela criação de novo conhecimento e treinamento de solucionadores de problemas, as universidades dão suporte à formação de start-ups. Para os autores, dado que a maioria das start-ups tende a ser de pequeno porte (e, por conseguinte, sejam improváveis de usar universidades), poder-se-ia esperar que somente as start-ups baseadas em ciência e aquelas que despendem recursos em P\&D sejam propensas a usar universidades. É interessante notar que Laursen e Salter (2004) e Cardamone e Pupo (2015) não puderam dar suporte à expectativa geral de que as empresas start-ups são as maiores usuárias do conhecimento de universidades em suas atividades inovativas $^{2}$.

É importante salientar que são escassos os trabalhos que abordaram a interação U-E especificamente a partir do recorte do porte da firma interativa. Santoro e Chakrabarti (2002), em um estudo de campo multimétodos nos Estados Unidos, identificaram que firmas maiores mais mecanicísticas, especialmente aquelas em setores industriais intensivos em recursos, usam a transferência de conhecimento e os relacionamentos de suporte à pesquisa para construir competências em áreas tecnológicas não centrais (non-core technologies). Em contraste, firmas menores mais orgânicas, particularmente aquelas em setores industriais de alta tecnologia, enfocam mais a resolução de problemas em áreas tecnológicas centrais (core technologies), através de transferência de tecnologia e de relacionamentos de pesquisa cooperativos.

Dito de outro modo, os autores encontraram que as grandes firmas têm maior intensidade de transferência de conhecimento e relacionamentos de suporte à pesquisa com a finalidade de fortalecer habilidades e conhecimentos, bem como ganhar acesso às instalações universitárias para avançar em tecnologias não centrais (non-core technologies). Em contraste, as pequenas firmas têm uma maior intensidade de transferência de tecnologia e relacionamentos de pesquisa cooperativos com a finalidade de fortalecer habilidades e conhecimentos, ademais de ganhar acesso às instalações da universidade para avançar em tecnologias centrais (core technologies).

Fontana et al. (2003) encontraram, com base no survey KNOW, que enfocou as PMEs de sete países da União Européia, evidência direta de que as organizações públicas de pesquisa encontram-se entre as fontes de informação menos importantes para as ideias inovativas e para a conclusão da inovação de PMEs. Os autores salientaram que a contribuição das organizações públicas de pesquisa para a fase de conclusão da inovação dessas empresas (período de tempo durante o qual uma inovação está sendo desenvolvida até a finalização) é similar à fase de ideias inovativas. Entretanto, se a fonte externa de informação mais importante para as PMEs é considerada na análise, tem-se que, para certos setores, as organizações públicas de pesquisa contribuem mais para a fase de conclusão da inovação do que para a fase de ideias inovativas.

Fontana et al. (2003) apontaram também que a maioria das PMEs não tem recursos ociosos (elas não são grandes o suficiente) para desenvolver relacionamentos com organizações públicas de pesquisa, apesar de algumas poucas firmas terem períodos de interação intensiva com estes agentes do SNI para satisfazer necessidades específicas. Embora as organizações públicas de pesquisa não desempenhem um papel central no processo inovativo de PMEs, cerca de metade das firmas na amostra dos autores desenvolveu projetos cooperativos de $\mathrm{P} \& \mathrm{D}$ com essas organizações.

Os autores identificaram dois principais fenômenos referentes aos fatores específicos à firma, ao setor e ao país que explicam a existência e a extensão dos projetos de P\&D cooperativos entre PMEs e organizações públicas de pesquisa. O primeiro diz respeito à relação entre a probabilidade de se formar colaborações em P\&D com organizações públicas de pesquisa e o tamanho da firma. Seus resultados

2 Todavia, Laursen e Salter (2004) salientaram que quando sua amostra é dividida em duas categorias de empresas start-ups, pode-se detectar tal relação entre as menores (com menos de 52 empregados). 
sugerem que a probabilidade depende do "tamanho absoluto" da firma, ou seja, as firmas maiores têm uma probabilidade muito maior de colaboração em P\&D. Entretanto, os autores salientam que o número de cooperações em P\&D não é afetado pelo "tamanho absoluto" da firma, mas pelo "tamanho relativo" medido pelo emprego em P\&D. Salienta-se, assim, que a intensidade em P\&D afeta a propensão da firma no engajamento em projetos de $\mathrm{P} \& \mathrm{D}$, bem como na extensão de seu engajamento na cooperação.

O segundo fenômeno refere-se à abertura (openness) das firmas, isto é, à sua disposição para buscar, sinalizar e avaliar (screen) o ambiente externo pela busca de publicações em bases de dados, pelo patenteamento e pela participação em programas subsidiados pelo governo. Os resultados de Fontana et al. (2003) sugerem que a confiança nas publicações para a aquisição de conhecimento afeta a probabilidade da firma entrar em uma colaboração com uma organização pública de pesquisa, mas não o nível de colaboração desenvolvido. As firmas que patenteiam para proteger a inovação (e sinalizar competências) também têm uma maior probabilidade de colaborar e um maior nível de colaboração com organizações públicas de pesquisa. Adicionalmente, seus resultados sugerem que as firmas que receberam subsídios públicos têm uma maior probabilidade de desenvolver cooperação em P\&D com organizações públicas de pesquisa e um número maior de colaborações, apesar do impacto dos subsídios na extensão da colaboração ser mediado por efeitos específicos ao país.

Povoa e Monsueto (2011) realizaram, com base em um survey com firmas interativas no DGP/CNPq (BR Survey) um exercício econométrico relacionado à hipótese schumpeteriana de que a tendência a inovar cresce com o tamanho da firma para um conjunto de empresas que interagem com universidades e IPPs. Os autores notaram que independentemente da categoria de tamanho da empresa, a taxa de inovação em produto é superior à de inovação em processo, embora as grandes empresas apareçam como sendo mais inovadoras tanto em produto como em processo. O padrão de inovação entre micro, pequenas e médias empresas encontrado na amostra é bastante similar. Ademais, seus resultados sugerem que o porte tem uma relação significativa e positiva com a propensão a inovar em produto. Entretanto, o mesmo não se verifica com a mesma consistência para inovações de processo.

Outro resultado dos autores é o de que quanto menor a empresa, menos ela recorre às universidades e IPPs para sugerir novos projetos. Entretanto, essa relação não se verifica quando se trata de concluir projetos, posto que as micro e pequenas empresas conferem uma importância a essa fonte de informação semelhante às grandes empresas. Quanto às razões apontadas pelas firmas como muito importantes para a colaboração com universidades e IPPs, Povoa e Monsueto (2011) destacaram a maior importância atribuída pelas grandes empresas à transferência de tecnologia das universidades e à busca de conselhos tecnológicos do que pelas micro e pequenas empresas. Apenas dois motivos para colaboração com universidades e IPPs foram considerados mais importantes pelas micro e pequenas empresas do que pelas grandes: contato com estudantes e recebimento de ajuda no controle de qualidade. Ademais, as micro, pequenas e grandes empresas atribuem praticamente a mesma importância à realização de testes e à utilização dos recursos laboratoriais disponíveis nas universidades e IPPs como importante elemento para a cooperação U-E.

Rapini (2007) encontrou no Censo 2002 do DGP/CNPq que, em termos da colaboração com os grupos de pesquisa (GPs), as micro e grandes empresas apresentaram as maiores participações relativas, sendo seguidas pelas médias empresas. Além disso, as microempresas cooperaram mais com universidades do que as grandes empresas. A autora identificou também que os relacionamentos U-E ocorreram em maior frequência com grandes e microempresas. Segundo Rapini et al. (2007), se, por um lado, esse padrão replica o identificado na literatura, por outro, é distinto o comportamento das pequenas empresas, que se mostraram como as menos interativas. As grandes empresas têm a maior participação relativa na transferência de serviços e produtos para os GPs, possivelmente por disporem de maiores recursos e capacidades.

No que tange aos tipos de relacionamentos oriundos dos GPs para as empresas de acordo com o tamanho, Rapini (2007) observou, primeiramente, o maior montante das atividades de "Pesquisa científica de uso imediato" no conjunto dessas atividades destinadas às microempresas que são superiores ao verificado no demais estratos de firmas. Para a autora, isso sugere que as microempresas, face à ausência de atividades de pesquisa internas, demandam pesquisas de caráter mais aplicado das universidades e dos IPPs. Em segundo lugar, pode-se inferir uma maior relevância da pesquisa básica no 
início das atividades das firmas, que perde importância relativa à medida que a firma cresce. De encontro a essa hipótese, tem-se ainda a proporção relevante de "Transferência de tecnologia" dos GPs para as microempresas.

Ainda segundo Rapini (2007), as grandes empresas apropriaram-se mais em "Pesquisas científicas sem uso imediato" do que as demais empresas, podendo isso estar relacionado à maior possibilidade de explorarem bases de conhecimento externas. Todavia, o mesmo não é observado em termos dos relacionamentos provenientes das empresas para os GPs. Por um lado as grandes empresas transferiram mais tecnologia para os GPs do que as micro e pequenas empresas. Por outro lado, as microempresas apresentam participação significativa no desenvolvimento de softwares para os GPs. Já o "Treinamento de pessoal” do grupo nas empresas tem a mesma participação nas micro e médias empresas, sugerindo que elas estariam se engajando em estratégias de aumento de capacitação da base do conhecimento, ainda que sejam menos expressivos os treinamentos realizados pelos GPs para as empresas (RAPINI 2007).

\section{UMA CONTEXTUALIZAÇÃO DAS ATIVIDADES INOVATIVAS DAS PMES BRASILEIRAS}

\subsection{Caracterização geral do processo inovativo em pequenas e médias empresas brasileiras}

Na PINTEC/IBGE de 2011, das 128.699 empresas industriais brasileiras com dez ou mais pessoas ocupadas, 45.950 realizaram algum tipo de inovação, representando uma taxa de inovação de 35,7\%, 2,9 pontos percentuais inferiores à taxa de inovação obtida em 2008. Os dados da Tabela 1 evidenciam que a taxa de inovação é mais elevada nas empresas de maior porte e que, em geral, as empresas inovaram mais em processo do que em produto. Desses dados, infere-se que o porte da empresa tem relação estreita com seu desempenho inovador. Na medida em que o tamanho da empresa aumenta, eleva-se também a taxa de inovação em produto e em processo, sendo as PMEs as que apresentaram as menores taxas de inovação.

\section{Tabela 1}

Desempenho inovador das empresas industriais brasileiras por faixa de pessoal ocupado, Brasil, 2011 (totais e taxa de inovação).

\begin{tabular}{|c|c|c|c|c|c|c|c|c|}
\hline & & Empr & resas & & & de inovaç & $(\%)$ & \\
\hline Faixa d & pessoal & Total & Inovadoras & Geral & Produto & $\begin{array}{c}\text { Produto } \\
\text { novo } \\
\text { mercado } \\
\text { nacional }\end{array}$ & Processo & $\begin{array}{c}\text { Processo } \\
\text { novo } \\
\text { mercado } \\
\text { nacional }\end{array}$ \\
\hline & De 10 a 29 & 83.856 & 28.391 & $33,86 \%$ & $17,15 \%$ & $2,73 \%$ & $30,21 \%$ & $1,55 \%$ \\
\hline & De 30 a 49 & 19.125 & 6.526 & $34,12 \%$ & $16,52 \%$ & $4,92 \%$ & $30,07 \%$ & $1,28 \%$ \\
\hline Pequena & De 50 a 99 & 14.355 & 5.655 & $39,39 \%$ & $17,47 \%$ & $5,55 \%$ & $34,56 \%$ & $4,19 \%$ \\
\hline & $\begin{array}{l}\text { De } 100 \text { a } \\
249\end{array}$ & 7.024 & 3.048 & $43,39 \%$ & $22,56 \%$ & $7,98 \%$ & $38,53 \%$ & $5,98 \%$ \\
\hline Média & $\begin{array}{l}\text { De } 250 \text { a } \\
499\end{array}$ & 2.110 & 1.082 & $51,29 \%$ & $33,08 \%$ & 11,89\% & $45,95 \%$ & $8,97 \%$ \\
\hline Grande & $\begin{array}{l}\text { Com } 500 \text { e } \\
\text { mais }\end{array}$ & 2.230 & 1.249 & $55,99 \%$ & $42,57 \%$ & $20,70 \%$ & $48,43 \%$ & $17,16 \%$ \\
\hline Total & & 128.699 & 45.950 & $35,70 \%$ & $18,09 \%$ & $4,12 \%$ & $31,70 \%$ & $2,44 \%$ \\
\hline
\end{tabular}

Fonte: PINTEC (2011), elaboração própria.

A análise da taxa de inovação segundo o referencial de mercado mostra que embora 18,1\% das empresas industriais tenham inovado em produto, apenas 4,1\% implementaram produto novo ou substancialmente aperfeiçoado para o mercado nacional. Assim, se observado o grau de novidade do produto, o desempenho das PMEs é ainda inferior ao das grandes empresas. Ao verificar que, entre os resultados da PINTEC 2008 e da PINTEC 2011, houve um crescimento relativo da inovação em processo, em detrimento da inovação em produto, reforça-se o fato de que os esforços de inovação no país se caracterizam como de atualização e modernização. 


\subsection{Problemas e obstáculos à inovação em pequenas e médias empresas brasileiras}

A análise das duas últimas edições da PINTEC/IBGE mostra que a taxa de inovação caiu de 38,1\% na PINTEC 2008, para 35,7\% na PINTEC 2011. Ao comparar a incidência de inovação entre essas pesquisas, infere-se que houve queda em pontos percentuais nas taxas de inovação (geral e de produto) em praticamente todos os portes de empresas industriais. De modo geral, as maiores quedas em pontos percentuais deram-se entre as empresas de grande porte.

Além da redução das taxas de inovação, a proporção de PMEs inovadoras que disseram ter encontrado algum tipo de problema ou obstáculo relevante foi de 46,8\% em 2011, o que indicou crescimento em relação a 2008 (44,2\%). Ou seja, além de perceber-se um aumento da proporção de empresas não inovadoras, cresceu, em relação ao conjunto menor de empresas inovadoras, o número de empresas que enfrentaram obstáculos relevantes para inovar no período pós-crise financeira internacional.

Para as empresas que não se envolveram com projetos inovadores nos períodos 2006-2008 e 2009 2011, as principais razões foram listadas na Tabela 2. As condições de mercado, referentes à deficiência de demanda (agregada e/ou setorial) e estrutura de oferta (concorrencial ou capacidade instalada) (IBGE, 2011), apareceram como principal obstáculo à inovação para o conjunto de PMEs (64,4\%). Esse obstáculo foi comum para todos os portes de empresas, correspondendo ao principal motivo para mais de $50 \%$ das empresas do total de cada faixa de porte não inovarem.

Tabela 2

Razões para não inovar, considerando-se o porte das empresas em atividades selecionadas da indústria e dos serviços, Brasil - 2006-2008 e 2008-2011

\begin{tabular}{|c|c|c|c|c|c|c|c|c|}
\hline $\begin{array}{c}\text { Motivos para não } \\
\text { inovar }\end{array}$ & \multicolumn{2}{|c|}{ Pequena } & \multicolumn{2}{|c|}{ Média } & \multicolumn{2}{|c|}{ Grande } & \multicolumn{2}{|c|}{$\begin{array}{c}\text { Total de PMEs que } \\
\text { não inovaram }\end{array}$} \\
\hline & $\begin{array}{c}\text { PINTEC } \\
2008 \\
\end{array}$ & $\begin{array}{c}\text { PINTEC } \\
2011 \\
\end{array}$ & $\begin{array}{c}\text { PINTEC } \\
2008 \\
\end{array}$ & $\begin{array}{c}\text { PINTEC } \\
2011 \\
\end{array}$ & $\begin{array}{c}\text { PINTEC } \\
2008 \\
\end{array}$ & $\begin{array}{c}\text { PINTEC } \\
2011 \\
\end{array}$ & $\begin{array}{c}\text { PINTEC } \\
2008 \\
\end{array}$ & $\begin{array}{c}\text { PINTEC } \\
2011 \\
\end{array}$ \\
\hline $\begin{array}{l}\text { Por causa de } \\
\text { condições de } \\
\text { mercado }\end{array}$ & $\begin{array}{r}32.341 \\
55,60 \%\end{array}$ & $\begin{array}{r}47.819 \\
64,70 \%\end{array}$ & $\begin{array}{r}2.470 \\
58,90 \%\end{array}$ & $59,20 \%$ & $56,70 \%$ & $55,00 \%$ & $\begin{array}{c}35.077 \\
55,80 \%\end{array}$ & $\begin{array}{l}50.645 \\
64,40 \%\end{array}$ \\
\hline $\begin{array}{c}\text { Por causa de } \\
\text { inovações prévias }\end{array}$ & $\begin{array}{c}9.007 \\
15,50 \%\end{array}$ & $\begin{array}{l}10.668 \\
14,40 \%\end{array}$ & $\begin{array}{c}835 \\
19,90 \%\end{array}$ & $\begin{array}{c}970 \\
20,30 \%\end{array}$ & $\begin{array}{c}101 \\
21,50 \%\end{array}$ & $\begin{array}{c}225 \\
24,40 \%\end{array}$ & $\begin{array}{r}9.944 \\
15,80 \%\end{array}$ & $\begin{array}{l}11.638 \\
14,80 \%\end{array}$ \\
\hline $\begin{array}{l}\text { Por causa de outros } \\
\text { fatores impeditivos }\end{array}$ & $\begin{array}{c}16.843 \\
28,90 \%\end{array}$ & $\begin{array}{l}15.406 \\
20,80 \%\end{array}$ & $21,20 \%$ & $\begin{array}{c}981 \\
20,50 \%\end{array}$ & $\begin{array}{c}102 \\
21,80 \%\end{array}$ & $\begin{array}{c}189 \\
20,50 \%\end{array}$ & $\begin{array}{c}17.837 \\
28,40 \%\end{array}$ & $\begin{array}{l}16.387 \\
20,80 \%\end{array}$ \\
\hline $\begin{array}{l}\text { Total de empresas } \\
\text { que não inovaram }\end{array}$ & 58.191 & 73.893 & 4.196 & 4.776 & 470 & 921 & 62.857 & 78.670 \\
\hline
\end{tabular}

Fonte: IBGE, 2011 e 2013, elaboração própria

Nota: Os percentuais representam a quantidade de empresas inovadoras ou não inovadoras que atribuíram alta ou média importância aos fatores listados. O 'Total’ refere-se ao número total de empresas inovadoras ou não inovadoras que atribuíram alguma importância (baixa, média ou alta) a cada um dos fatores listados.

Destaca-se que, em relação à PINTEC 2008, o percentual de PMEs que apontou as 'condições de mercado’ como principal obstáculo à inovação, na PINTEC de 2011, cresceu de 55,6\% para 64,7\% no caso das pequenas empresas e, no caso das empresas de médio porte, esse percentual subiu de 58,9\% para $59,2 \%$. Esse dado sugere que, no período pós-crise financeira internacional, um componente de natureza 
conjuntural pode ter agravado as "condições de mercado" enquanto uma barreira relevante para que as PMEs não inovem no Brasil.

Os resultados da Tabela 2 indicam também que a realização de inovações prévias, como razão para não inovar, está mais presente nas grandes empresas. Em termos comparativos, para as grandes empresas, a razão para não inovar devido às inovações prévias foi mais relevante do que para as demais (24,4\% para as grandes, 20,3\% para as médias e $14,4 \%$ para as pequenas). Adicionalmente, tem-se que na PINTEC 201116.387 empresas (20,8\%) de pequeno e médio porte (PMEs) atribuíram outros fatores à dificuldade de inovar. Diferentemente das grandes empresas, para as PMEs 'outros fatores impeditivos' aparece como a segunda principal razão para não inovar, atrás apenas de 'condições de mercado'.

A tabela 3 apresenta todos estes outros fatores que impediram o desenvolvimento, implementação da inovação apresentados pelas PMEs que inovaram e que não inovaram nas duas últimas edições do survey de inovação. Tanto para as PMEs inovadoras, como para as PMEs não inovadoras, o fator que exerceu maior impacto negativo sobre a atividade inovativa foi o custo elevado da inovação. Em segundo lugar, o principal fator apontado pelas PMEs inovadoras foi a falta de pessoal qualificado, enquanto que para as PMEs não inovadoras, o segundo principal motivo foram os riscos econômicos excessivos. Em quarto lugar, para ambas, empresas inovadoras e não inovadoras, o fator impeditivo foi a escassez de fontes apropriadas de financiamento.

\section{Tabela 3}

\section{Problemas e obstáculos às atividades inovativas em pequenas e médias empresas inovadoras e não} inovadoras, Brasil, 2006-2008 e 2008-2011 


\begin{tabular}{|c|c|c|c|c|}
\hline \multirow{2}{*}{$\begin{array}{l}\text { Fatores } \\
\text { (alta e média } \\
\text { importância }\end{array}$} & \multicolumn{2}{|c|}{ PINTEC 2008} & \multicolumn{2}{|c|}{ PINTEC 2011} \\
\hline & $\begin{array}{c}\text { Inovadoras } \\
(\%)\end{array}$ & $\begin{array}{c}\text { Não inovadoras } \\
(\%)\end{array}$ & $\begin{array}{c}\text { Inovadoras } \\
(\%)\end{array}$ & $\begin{array}{c}\text { Não inovadoras } \\
(\%)\end{array}$ \\
\hline $\begin{array}{l}\text { Riscos } \\
\text { econômicos } \\
\text { excessivos }\end{array}$ & 63,2 & 67,7 & $71,80 \%$ & $66,90 \%$ \\
\hline $\begin{array}{l}\text { Elevados custos } \\
\text { da inovação }\end{array}$ & 70,6 & 74,9 & $81,80 \%$ & $78,50 \%$ \\
\hline $\begin{array}{l}\text { Escassez de fontes } \\
\text { de financiamento }\end{array}$ & 50 & 53,1 & $63,60 \%$ & $57,40 \%$ \\
\hline $\begin{array}{l}\text { Rigidez } \\
\text { organizacional } \\
\end{array}$ & 30,2 & 19,7 & $36,40 \%$ & $33,30 \%$ \\
\hline $\begin{array}{l}\text { Falta de pessoal } \\
\text { qualificado }\end{array}$ & 57,2 & 42 & $72,60 \%$ & $60,70 \%$ \\
\hline $\begin{array}{l}\text { Falta de } \\
\text { informação sobre } \\
\text { tecnologia }\end{array}$ & 35,7 & 23,3 & $44,50 \%$ & $35,50 \%$ \\
\hline $\begin{array}{l}\text { Falta de } \\
\text { informação sobre } \\
\text { mercados }\end{array}$ & 31,6 & 20 & $36,10 \%$ & $32,60 \%$ \\
\hline $\begin{array}{l}\text { Escassas } \\
\text { possibilidades de } \\
\text { cooperação com } \\
\text { outras empresas/ } \\
\text { instituições }\end{array}$ & 30,8 & 32,5 & $41,70 \%$ & $34,80 \%$ \\
\hline $\begin{array}{l}\text { Dificuldade para se } \\
\text { adequar a padrões, } \\
\text { normas e } \\
\text { regulamentações }\end{array}$ & 31,4 & 28,1 & $44,80 \%$ & $36,30 \%$ \\
\hline $\begin{array}{l}\text { Fraca resposta dos } \\
\text { consumidores } \\
\text { quanto a novos } \\
\text { produtos }\end{array}$ & 29 & 20,5 & $36,40 \%$ & $31,40 \%$ \\
\hline $\begin{array}{l}\text { Escassez de } \\
\text { serviços técnicos } \\
\text { externos } \\
\text { adequados } \\
\end{array}$ & 36,7 & 29,8 & $44,80 \%$ & $40,60 \%$ \\
\hline $\begin{array}{l}\text { Centralização da } \\
\text { atividade inovativa } \\
\text { em outra empresa } \\
\text { do grupo }\end{array}$ & 1,5 & 1,3 & $1,70 \%$ & $1,20 \%$ \\
\hline
\end{tabular}

Fonte: IBGE, 2011 e 2013, elaboração própria

Nota: Os percentuais representam a quantidade de empresas inovadoras ou não inovadoras que atribuíram alta ou média importância aos fatores listados. O 'Total' refere-se ao número total de empresas inovadoras ou não inovadoras que atribuíram alguma importância (baixa, média ou alta) a cada um dos fatores listados.

O elevado percentual de PMEs que atribuíram média ou alta importância aos elevados custos da inovação pode indicar que os diversos programas do governo federal não estão conseguindo atingir um número significativo destas empresas. É interessante notar que, em relação aos resultados obtidos na PINTEC 2008, a falta de pessoal qualificado ganhou importância relativa na PINTEC 2011, se comparada a outros fatores impeditivos como a escassez de fontes apropriadas de financiamento, sobretudo no caso das empresas não inovadoras, cujo percentual cresceu de 42,4\% para 60,7\%.

Os dados da Tabela 3 sugerem que os principais obstáculos vinculados à natureza econômica (custos, riscos e fontes de financiamento apropriadas) parecem funcionar como a segunda grande barreira à inovação nas PMEs brasileiras (atrás apenas das 'condições de mercado'), somados ao problema da escassez de pessoal qualificado, que, como já se observou, ganhou proeminência na última pesquisa 
realizada pelo IBGE. Uma vez alcançada a inovação, os obstáculos concernentes a deficiências técnicas, a problemas de informação (falta de informação sobre tecnologia e mercados), a problemas internos à empresa (rigidez organizacional), a problemas de regulação (dificuldades para se adequar a padrões, normas e regulamentações), a problemas de demanda, escassas possibilidades de cooperação e centralização da atividade inovativa em outra empresa do grupo tornam-se mais significativos. Para todos os fatores mencionados acima, os percentuais de insatisfação das empresas inovadoras foram mais elevados que os das não inovadoras ${ }^{3}$.

\section{ALGUMAS OBSERVAÇÕES METODOLÓGICAS}

Para esta pesquisa, a unidade de investigação é a firma interativa com os GPs do DGP/CNPq. Nessa perspectiva, a montagem da base do Censo 2010 pôde identificar a existência (ou não) de interações com firmas/instituições. As variáveis disponíveis na base de dados referem-se: (1) aos GPs científicos; (2) às firmas/instituições com as quais interagem; e (3) aos tipos de relacionamento.

As bases de informação utilizadas neste trabalho, que permitiram aferir aspectos da cooperação entre as PMEs e universidades e IPPs no Brasil, são o DGP/CNPq e a Relação Anual de Informações Sociais do Ministério do Trabalho e Emprego (RAIS/MTE) ${ }^{4}$.

Os dados foram obtidos do Censo 2010 do DGP/CNPq. As PMEs analisadas neste trabalho são aquelas que cooperaram, no Censo de 2010, com GPs das áreas de Engenharias ${ }^{5}$ e Ciências Agrárias. Estas são as duas áreas do conhecimento que apresentam o maior número de relacionamentos com o setor produtivo, conforme autores que investigaram as interações U-E no Brasil com base nos Censo 2004 (SUZIGAN et al., 2009; RIGHI e RAPINI, 2011) e 2008 (RAPINI et al, 2015).

Segundo Metcalfe (2003), a engenharia e a tecnologia aplicada são relativamente menos dirigidas (driven) pela teoria, dependendo mais da acumulação de tentativa e erro em contextos práticos, e a falha no uso é frequentemente um evento significativo gerador de conhecimento. Este conhecimento é acumulado, primordialmente, mas não exclusivamente, nas firmas. Suzigan et al. (2009) acrescentaram que a elevada parcela dos grupos e firmas interativos das Ciências Agrárias mostra a importância da pesquisa acadêmica como uma fonte de conhecimento para as firmas agrícolas.

Para classificar as empresas interativas no DGP/CNPq segundo a característica estrutural porte, foi adotado o critério de classificação do Serviço Brasileiro de Apoio às Micro e Pequenas Empresas (Sebrae) do porte do estabelecimento em função do número de pessoas ocupadas ${ }^{6}$. Portanto, para a composição da base de dados referente às PMEs brasileiras interativas com GPs, originada do cruzamento das informações do DGP/CNPq e da RAIS/MTE, utilizou-se o recorte de CNPJs das instituições parceiras relatadas pelos líderes dos GPs com até 500 empregados. Aplicado o recorte de 500 empregados por CNPJ na base de dados de firmas interativas, a tabulação de dados indicou um conjunto de 2049 instituições parceiras que interagiram com 1330 GPs do CNPq no Censo de 2010.

Adicionalmente, foram aplicados dois filtros à base de dados. O primeiro se refere ao recorte dos dados das instituições parceiras a partir do "CNPJ Raiz", composto pelos oito primeiros números que formam o número de inscrição da empresa no Cadastro Nacional da Pessoa Jurídica (a "raiz", que identifica a empresa). Procurou-se dessa forma, eliminar a diferenciação entre matriz e filial(is), representada pelos 4 dígitos seguintes, que identificam uma unidade de atuação da empresa (ou seja, um

\footnotetext{
${ }^{3}$ De toda forma, note-se que, de modo geral, e, sobretudo, no caso das PMEs que não conseguiram desenvolver algum projeto inovador, os principais problemas e obstáculos à inovação ainda estão relacionados à estrutura institucional e macroeconômica e não a fatores microeconômicos.

${ }^{4}$ Esta base de dados foi montada pela equipe coordenada pelo Prof. Renato Garcia (IE/UNICAMP) no âmbito do projeto “Geografia e inovação: Uma análise dos efeitos da aglomeração industrial e suas implicações de políticas”. É importante salientar que foram necessários cruzamentos de informações das firmas interativas do DGP/CNPq com as informações da RAIS. A partir do cruzamento dos CNPJs das empresas interativas da base do DGP e da RAIS foram obtidas, nessa última base, as seguintes informações sobre as empresas interativas com os GPs: a) porte; b) setor de atividade econômica; e) UF.

${ }^{5}$ Cabe notar que alguns destes pontos de interação entre campos de ciência e engenharia e setores industriais são resultados da existência de leis brasileiras que vinculam benefícios fiscais à dispêndios em P\&D, parte deles compartilhados com universidades e institutos de pesquisa. Este é o caso de Equipamentos de Computação, software e Eletricidade (SUZIGAN et al, 2009).

6 Esse critério de classificação dos estabelecimentos segundo porte foi definido pelo Sebrae por meio do texto: "Nota Metodológica para Definição dos Números Básicos de MPE” (SEBRAE, 2006, citado por SEBRAE, 2013, p. 06).
} 
endereço de atividade da pessoa jurídica), correspondem ao $\mathrm{n}^{0}$ da filial. Aplicado este filtro a todas as empresas da base, todas as informações da base de dados referentes à instituição parceira passaram a abranger no "CNPJ raiz" as informações referentes a todos os estabelecimentos inscritos (filiais e matrizes). Todas as instituições parceiras de GPs do Censo 2010, cujos “CNPJs Raiz” corresponderam a um número de empregados superior a 500, foram eliminadas da base de dados.

Às empresas restantes na base de dados do DGP/CNPq foi aplicado um segundo filtro. Suas informações foram cruzadas com o Anuário Melhores e Maiores de 2010, de EXAME, no qual foi possível identificar as 1.000 maiores empresas do Brasil pelo critério do desempenho da receita líquida em dólares, excluídas as empresas do setor financeiro. Todas aquelas empresas da base de dados que apresentaram o número de empregados superior a 500 no referido Anuário foram eliminadas da base de PMEs interativas do DGP/CNPq. Após a aplicação dos dois filtros nas 2049 instituições parceiras dos GPs do CNPq no Censo de 2010 encontram-se presentes na base de dados da pesquisa 1822 PMEs interativas.

Com a finalidade de explorar os fatores ao nível da firma que afetam a propensão das PMEs a cooperar com universidades e IPPs em seus processos inovativos foram usadas algumas variáveis referentes às características estruturais das firmas e dos seus relacionamentos $U$-E que podem determinar a propensão de seu engajamento na cooperação com universidades e IPPs.

Primeiramente, dado que a propensão a buscar ativamente vínculos com universidades pode ser influenciada pelos setores, que constituem uma proxy para a oportunidade tecnológica (CARDAMONE e PUPO, 2015), foi incluído na análise um indicador de setor de atividade econômica. Segundo a literatura, a contribuição da pesquisa pública à P\&D industrial varia através de setores econômicos, de modo que alguns deles contam mais fortemente com a pesquisa universitária (KLEVORICK et al., 1995; COHEN et al., 2002; SCHARTINGER et al., 2002). Foram aplicadas as seguintes tipologias setoriais à Classificação Nacional de Atividade Econômica do (CNAE/IBGE): a) Setores baseados na ciência e intensivos em P\&D; b) Setores Dominados por fornecedores; c) Setores Fornecedores especializados; d) Setores Intensivos em economias de escala e de produção em massa; e) Setores Knowledge intensive business sectors (KIBs) ou seja, serviços empresariais intensivos em conhecimento; f) Outros Serviços; g) Intermediação financeira, seguros, previdência e serviços relacionados; h) Administração pública, defesa e seguridade social; i) Agricultura, pecuária, silvicultura e exploração florestal; j) Pesca, aquicültura e serviços relacionados; k) Construção; e l) Outros. A classificação foi feita pelo nível de intensidade tecnológica setorial de acordo com Campos e Urraca Ruiz (2009), para os quatro primeiros tipos de empresas industriais classificadas e com Freire (2006) e Kubota (2009) para a classificação dos KIBs. Os demais tipos foram classificações definidas pela autora, no sentido de compatibilizar as informações disponibilizadas na base do DGP.

Em segundo lugar, dado que a intensidade em P\&D da firma aumenta a incidência de exploração de conhecimento de universidades/laboratórios governamentais em suas atividades inovativas (MOHNEN e HOAREAU, 2003; LAURSEN e SALTER, 2004; CARDAMONE e PUPO, 2015), foi inserido na análise um indicador de $P \& D$ das firmas. O número de empregados com ensino superior ou mais em relação ao total de empregados das firmas foi utilizado como proxy da mensuração do esforço de $\mathrm{P} \& \mathrm{D}$. Alguns autores como Bruneel et al. (2010) e GARCIA et al. (2014) utilizaram a qualificação da mão de obra como uma proxy para a capacidade de absorção da firma. Espera-se que firmas com trabalhadores mais qualificados tenham maior propensão a inovar (KUBOTA, 2009).

Em terceiro lugar, adotou-se como proxy da existência de vínculos cooperativos prévios entre a PME e o GP a existência de interação U-E no Censo anterior do DGP (Censo 2008). Segundo MoraValentin et al. (2004), pode-se dizer que há vínculos (links) prévios quando, no passado, houve alguma colaboração em atividades similares ou quando os parceiros colaboraram previamente em outras ocasiões.

Em quarto lugar, dado que o DGP/CNPq permite qualificar as interações U-E em termos de seu tipo e densidade, os tipos de relacionamentos da base foram reclassificados em duas formas diferentes: a) Relacionamento bidirecional: relacionamentos pesquisa científica de uso imediato e sem uso imediato dos resultados; e b) Relacionamento unidirecional: transferência de tecnologia, desenvolvimento de software, engenharia não rotineira, consultoria e treinamento. Isso se justifica por que há importantes diferenças em termos da criação e difusão de conhecimento se a interação é baseada em uma simples prestação de 
serviços, tal como um teste de laboratório ou se a universidade e a indústria mantêm projetos de pesquisa colaborativa e conjunta, nos quais elas interagem e trocam não somente informação, mas também conhecimento (SUZIGAN et al., 2009). Este trabalho apoiou-se na compatibilização dos canais de transferência de conhecimento sugerida em Arza e Vasquez (2010) e Fernandes et al. (2010) com os tipos de relacionamento especificados na base do DGP, realizada por Caliari e Rapini (2014) e Rapini et al. (2015).

\section{A INTERAÇÃO U-E DE PMEs BRASILEIRAS: ALGUNS RESULTADOS DESCRITIVOS DO DGP/CNPQ}

Os resultados apresentados neste trabalho são preliminares e essencialmente descritivos em dois modos principais. Primeiramente, pela análise da base de dados com informações do DGP/CNPq e da RAIS/MTE, é possível mapear as firmas interativas com universidades e IPPs quanto ao setor de atividade e esforços inovativos. Em segundo lugar, os dados coletados e organizados dessa base de dados, com informações adicionais do DGP Censo 2008, permitem a identificação da existência de vínculos (links) prévios e dos tipos de relacionamentos U-E. Ambas as análises são apresentadas a seguir.

\subsection{As características estruturais das firmas interativas}

\section{Setor de atividade}

A análise das PMEs brasileiras interativas com universidades e IPPs, classificadas de acordo com o nível de intensidade tecnológica setorial, permite identificar que tais empresas pertencem não somente a setores industriais de alta intensidade tecnológica e a setores de serviços intensivos em conhecimento (Knowledge intensive business sectors, KIBs), mas também a setores de baixa e média intensidade tecnológica (conforme classificação da OCDE).

Primeiramente, destacam-se no conjunto de PMEs interativas com GPs do DGP/CNPq empresas dos setores de atividade caracterizados por menores oportunidades tecnológicas: a) setores industriais dominados por fornecedores (22,1\%), com destaque para a fabricação de produtos diversos (8,2\%) e produtos alimentícios $(6,1 \%)$; b) de outros serviços (que não os KIBs) $(19,8 \%)$, com destaque para as atividades associativas (9,4\%) e a produção e distribuição de eletricidade, gás e água (3.0\%); e c) de comércio (10,4\%), entre as quais as mais numerosas são as de comércio por atacado, representantes comerciais e agentes do comércio (5,9\%) e de comércio varejista e reparação de objetos pessoais e domésticos (4,1\%) (tabela 4). Além disso, é não desprezível a participação de PMEs dos setores de agricultura, pecuária, silvicultura e exploração florestal $(6,1 \%)$ no conjunto de empresas interativas.

Vale notar que Campos e Ruiz (2009) salientaram, com base nos dados da PINTEC 2000, que os setores tipicamente “dominados por fornecedores” não apresentam uma trajetória tecnológica específica, sendo que nesta categoria prevalecem inovações de processo com caráter incremental. Kubota (2009), utilizando os dados da Pesquisa da Atividade Econômica Paulista (Paep) 2001, acrescentou que as atividades que compõem o setor de serviços são muito variadas, assim como o grau de inovação tecnológica para o mercado destas empresas, destacando-se claramente os setores de telecomunicações, informática e pesquisa e desenvolvimento que integram a categoria dos KIBs, ou seja, dos serviços empresariais intensivos em conhecimento, discutida abaixo, sendo pouco expressiva nos demais setores de serviços ${ }^{7}$.

\section{Tabela 4}

\section{PMEs brasileiras interativas com grupos de pesquisa do Diretório de Grupos do CNPq, segundo padrões de setoriais de mudança tecnológica}

\footnotetext{
${ }^{7}$ Conforme Kubota (2009), nos setores de informática, serviços técnicos prestados às empresas e outros serviços existe um percentual elevado de firmas que são as principais desenvolvedoras das inovações. Apenas o setor de audiovisual poderia ser inequivocamente considerado dominado pelos fornecedores.
} 


\begin{tabular}{|c|c|c|}
\hline Setores & Total & $(\%)$ \\
\hline \multicolumn{3}{|l|}{ Setores dominados por fornecedores } \\
\hline Indústria extrativa & 20 & 1,1 \\
\hline Fabric. prod. alimenticios & 112 & 6,1 \\
\hline Fabric.bebidas & 14 & 0,8 \\
\hline Fabric. prod. texteis & 13 & 0,7 \\
\hline Confec. art. vestuário/acess. & 1 & 0,1 \\
\hline Couros, artef. couro e calçados & 7 & 0,4 \\
\hline Fabric. prod. madeira & 19 & 1,0 \\
\hline Fabric. papel, emb. e artef. papel & 8 & 0,4 \\
\hline Edição, impres. rep. de gravações & 1 & 0,1 \\
\hline Coque, comb. nucleares e álcool & 13 & 0,7 \\
\hline Fabric. art. borracha e plástico & 60 & 3,3 \\
\hline Fabric. prod. min. não-metálicos & 52 & 2,9 \\
\hline Fabric. prod. de metal & 59 & 3,2 \\
\hline Fabric. de artigos do mobiliário & 18 & 1,0 \\
\hline \multirow[t]{2}{*}{ Fabric. produtos diversos } & 6 & 8,2 \\
\hline & 403 & 22,1 \\
\hline
\end{tabular}

\section{Setores fornecedores especializados}

Fabric. celulose e out. pastas

Fabric. máq. e equipamentos

Fabric. mat. eletrôn. básico

Instr.méd.-hosp.,precisao/ópticos

Fabric. peças/acess. p/veículos

Fabric. out. equip. de transporte

$\begin{array}{cc}1 & 0,1 \\ 68 & 3,7 \\ 17 & 0,9 \\ 53 & 2,9 \\ 9 & 0,5 \\ 6 & 0,3 \\ 154 & 8,5\end{array}$

Setores intensivos em economias de escala e de produção em massa

Produtos siderurgicos

$8 \quad 0,4$

Metalurg. não-ferrosos/fundição

$11 \quad 0,6$

Setores baseados na ciência e intensivos em P\&D

Fabric.produtos químicos

19

Fabric. produtos farmacêuticos

\begin{tabular}{cc}
104 & 5,7 \\
39 & 2,1 \\
18 & 1,0 \\
42 & 2,3 \\
16 & 0,9 \\
$\mathbf{2 1 9}$ & $\mathbf{1 2 , 0}$ \\
\hline
\end{tabular}

Fabric. máq. escrit./equip. informát.

Fabric. máq. apar. e mat. elétrico

Knowledge Intensive Business Services (Kibs)

Atividad. informát. e serviç. relacionad.

Telecomunicações

Serviç. prestad. principalm. empresas

Pesquisa e Desenvolvimento

$\begin{array}{cc}82 & 4,5 \\ 7 & 0,4 \\ 110 & 6,0 \\ 42 & 2,3 \\ 241 & 13,2\end{array}$

\section{Outros Serviços}

Prod. e distribuiç. eletricidad, gás e agua

Alojam. e alimentaç.

Transport. terrestr.

Transport. aquaviár.

Atividad. anexas e auxiliar. dos transport. e agênc. de viagem

Atividad. imobiliár.

Aluguel veícul., máq. equip. s/ condut. ou operad. e de obj. pessoais e doméstic. 1

Educação

Saude e serviç. sociais

Serviç. Pessoais

Limpez. urban. e esgot. e atividad. relacionad. 


\section{PMEs brasileiras interativas com grupos de pesquisa do Diretório de Grupos do CNPq, segundo padrões de setoriais de mudança tecnológica}

\begin{tabular}{lcc}
\hline Intermediação financeira, seguros, previdência e serviços relacionados & 0,4 \\
Intermediação financeira & 7 & 0,1 \\
Atividad. auxiliar. intermediaç. financ., segur. previdênc. complement. & 2 & $\mathbf{0 , 5}$ \\
\hline Administraç. públic, defes. e seguridad. social & $\mathbf{9}$ & $\mathbf{2 , 8}$ \\
\hline Comércio; reparação de veículos automotores, objetos pessoais e domésticos & $\mathbf{5 1}$ & 0,4 \\
Comérc. e reparaç. de veíc. automotor. e motocliclet.; e comérc. varej. de combus & 8 & 5,9 \\
Com. Atacado, repr. comerc. e agent. do comerc & 107 & 4,1 \\
Com. varej. e reparaç. objet. pessoais e domest. & 74 & $\mathbf{1 0 , 4}$ \\
\hline Agricultura, pecuária, silvicultura e exploração florestal & $\mathbf{1 8 9}$ & $\mathbf{6 , 1}$ \\
\hline Pesca, aquicültura e serviços relacionados & $\mathbf{1 1 2}$ & $\mathbf{0 , 6}$ \\
\hline Construção & $\mathbf{1 1}$ & $\mathbf{2 , 6}$ \\
\hline Outros & $\mathbf{4 8}$ & $\mathbf{0 , 3}$ \\
\hline Total dos setores & $\mathbf{6}$ & $\mathbf{1 0 0 , 0}$ \\
\hline
\end{tabular}

Fonte: Elaboração própria a partir do DGP/CNPq e RAIS/MTE

A elevada participação de PMEs interativas na categoria dos setores "dominados por fornecedores”, que congrega os ramos tradicionais da indústria, com baixo dinamismo tecnológico, corrobora as evidências de trabalhos anteriores que, utilizando os dados da PINTEC (2000) (ALBUQUERQUE et al., 2005) e de surveys com empresas de Minas Gerais (MG Survey) (RAPINI et al., 2009) e empresas interativas com GPs do DGP/CNPq (BR Survey) (PINHO, 2011) encontraram que mesmo em setores de baixa e média intensidade tecnológica, tais como mineração e papel e celulose, as universidades e os IPPs brasileiros desempenham um importante papel no suporte à inovação das firmas.

Em segundo lugar, destacam-se na base do DGP/CNPq as PMEs interativas dos seguintes setores de atividade de maior intensidade tecnológica: 1) os Knowledge intensive business sectors (KIBs) $(13,2 \%)$, com destaque para os serviços prestados principalmente às empresas (6,0\%) e as atividades de informática e serviços relacionados (4,5\%); e 2) os setores industriais "baseados em ciência e intensivos em P\&D” (12,0\%), possuidores de maiores oportunidades tecnológicas, entre os quais desatacam-se as empresas produtoras de produtos químicos $(5,7 \%)^{8}$. Sobressaem-se também as PMEs dos setores "fornecedores especializados" (8,5\%), com maior participação das fabricantes de máquinas e equipamentos (3,7\%) e dos fabricantes de instrumentos médicos-hospitalares, precisão/ópticos (2,9\%) ${ }^{9}$.

No segundo conjunto de PMEs interativas encontram-se aquelas empresas comumente pertencentes aos setores de atividade econômica destacados pela literatura que investiga as interações U-E por mostrarem interações mais intensas com universidades e IPPs, quais sejam, as empresas de serviço intensivas em conhecimento (KIBs) (HIPP; GRUPP, 2005 MILES, 2007¹0; FREIRE, 2006; KUBOTA, 2009) ${ }^{11}$ e de setores industriais baseados em ciência (KLEVORICK et al, 1995; COHEN et al., 2002; SCHARTINGER et al., 2002; MOHNEN e HOAREAU, 2003; LAURSEN e SALTER, 2004, entre

\footnotetext{
${ }^{8}$ Campos e Ruiz (2009) caracterizam tais indústrias como intensivas no uso de fontes internas, destacando-se as atividades de P\&D. Os determinantes de conhecimento e aprendizado nas empresas destes setores são variados e incluem a influência das formas codificadas de aprendizagem e a interação com universidades e centros de pesquisa. Vale notar que o tipo de inovação predominante é a inovação de produto, com grande permeabilidade nos demais setores.

${ }^{9}$ Segundo Campos e Ruiz (2009, o padrão de inovação dos setores “Fornecedores especializados” é marcado pela ascendência de fontes internas de inovação, sendo comuns as práticas de Pesquisa \& Desenvolvimento (P\&D) e Desenvolvimento e Engenharia (D\&E), embora não se possa ignorar a relevância da aquisição de máquinas e equipamentos. As formas de conhecimento e aprendizagem das empresas são difusas, sendo que há um predomínio de inovações de produto de caráter incremental. Nota-se também que a proporção de empresas que atribuíram alta relevância para o aprendizado por interação é a maior dentre todos os agrupamentos de empresas.

10 Miles (2007) salienta que os setores de comércio e prestação de serviços possuem uma dinâmica inovativa distinta, decorrente de suas especificidades, que exigem maior envolvimento de pessoal das equipes de ambos os parceiros universidade e empresa.

${ }^{11}$ Segundo Kubota (2009), as universidades e os IPPS são fontes de informação particularmente importante para setor de P\&D.
} 
outros). É também este último conjunto de PMEs que abrange as empresas startups e de base tecnológica (EBTs), que, segundo a literatura fazem uso particular da pesquisa de instituições acadêmicas.

\section{Os esforços em $P \& D$}

No que diz respeito aos esforços de P\&D das PMEs interativas com GPs do CNPq, tomados pelo número de empregados com nível superior ou mais no total de empregados das firmas, as informações da RAIS/MTE indicam, primeiramente, que 41,1\% das empresas possuíam 9,9\% ou menos de seus empregados com este nível de qualificação (tabela 5). É importante ressaltar que do conjunto de PMEs interativas, 356 empresas, ou 19,5\% do total, não possuíam mesmo entre os seus recursos humanos, empregados com nível superior ou mais. Adicionalmente, tem-se que 28,4\% das PMEs interativas do DGP/CNPq possuíam de 10 a 39,9\% dos seus empregados com nível superior ou mais. Desse modo, esperar-se-ia que trabalhadores menos qualificados tenham menor propensão a inovar. Em segundo lugar, tem-se que apenas 4,9\% das PMEs interativas com GPs do DGP/CNPq apresentavam de 90 a $100 \%$ de seus recursos humanos com nível superior ou mais, sinalizando a realização de esforços mais expressivos de P\&D e maior capacidade de absorção.

\section{Tabela 5}

\section{PMEs brasileiras interativas com grupos de pesquisa do Diretório de Grupos do CNPq,} segundo faixas de empregados com nível superior ou mais

\begin{tabular}{l|c|c}
\hline Empregados com Ensino Superior ou mais no total de empreados (\%) & Empresas & $(\%)$ \\
\hline $90-100$ & 90 & 4,9 \\
$60-89,9$ & 213 & 11,7 \\
$40-59,9$ & 253 & 13,9 \\
$10-39,9$ & 518 & 28,4 \\
Menos que 9,9 & 748 & 41,1 \\
\hline Total & 1822 & 100,0 \\
\hline
\end{tabular}

Fonte: Elaboração própria a partir do DGP/CNPq e RAIS/TEM

A literatura salienta que empresas com maiores capacidades de absorção, uma habilidade para identificar, assimilar e aplicar conhecimento externo relevante e que é crítica para suas capacidades inovativas (COHEN e LEVINTHAL, 1990), tendem a buscar conhecimento externo e a melhor usufruir da interação desde o início. Todavia, os dados do DGP/CNPq indicam que é muito elevado o percentual de PMEs brasileiras interativas com baixa (ou nula) capacidade de absorção potencial e realizada, segundo Teixeira et al. (2016) ${ }^{12}$. Esse resultado é relevante, posto que maior capital humano deve aumentar a propensão da colaboração universitária, dado que ela aumenta a chance da absorção bem sucedida de conhecimento externo (LAURSEN et al., 2011).

Os resultados do DGP/CNPq sugerem por um lado, que a maior parte das PMEs interativas brasileiras possui escassos recursos internos que se traduzem em capacidade em $P \& D$, os quais são apontados pela literatura como uma pré-condição para a cooperação com universidades e IPPs. Ademais, na PINTEC/IBGE parcela significativa de PMEs aponta a falta de pessoal qualificado como um problema e obstáculo à inovação.

Particularmente quanto à mão de obra qualificada, Freel (2000) notou que, no caso das pequenas empresas, esse dilema é exacerbado pelos mesmos constrangimentos de recursos que inibem o recrutamento e o desenvolvimento da gestão. Pequenas empresas raramente são capazes de equiparar as taxas salariais e as oportunidades de desenvolvimento de carreira ou segurança no emprego àquelas vigentes no interior das grandes empresas e encontram-se em desvantagem no mercado de mão de obra qualificada (BOSWORTH, 1989 citado por FREEL, 2000, p. 62). Contudo, tal recurso é essencial para o sucesso da inovação, notavelmente durante os estágios iniciais de desenvolvimento de produto. O autor salientou ainda que outra consequência dos baixos níveis de habilidades técnicas relaciona-se à natureza

\footnotetext{
12 Segundo os autores, a mão de obra mais qualificada (pós-graduados) está relacionada a uma maior capacidade de absorção potencial e realizada.
} 
de auto-reforço da competência organizacional. Assim, a expectativa é de que as pequenas empresas tendam mais a identificar as habilidades dos empregados como um constrangimento à atividade inovativa e ao seu sucesso, sendo esse obstáculo mais difícil de ser superado pelas empresas desse porte (HEWITTDUNDAS, 2006).

Segundo Freel (2000), para muitas pequenas empresas, na ausência de especialistas funcionais ou de elevados (e amplos) níveis de competência interna, as atividades de busca de informação são proibitivamente custosas ou mal direcionadas e localizadas. Quando há menos bases de conhecimento a partir das quais construir competências (como os constrangimentos de recursos invariavelmente ditam), a consequência é sobre a especialização e à falta de robustez (FREEL, 1998 citado em FREEL, 2000, p.63). Ademais, as desvantagens de escala implicam que as pequenas empresas devem ter menos acesso às fontes externas de auxílio e informação para superar deficiências em recursos e habilidades internas.

Por outro lado, os dados do DGP/CNPq podem sinalizar também que tais empresas, ao possuírem menos recursos internos e, portanto, menor capacidade de absorção, necessitam significativamente de conhecimento externo, adquirido por meio de processos cooperativos ${ }^{13}$.

\section{A existência de vínculos (links) prévios}

O cruzamento das bases de dados de firmas interativas do DGP/CNPq - Censos 2010 e 2008 permitiu inferir que é elevado (56,6\%) o percentual de PMEs que interagiram com GPs nos dois períodos analisados. Segundo Mora-Valentin et al. (2004), a existência de vínculos (links) prévios se refere ao aprendizado em um relacionamento cooperativo. Dessa forma, aquelas organizações que colaboraram no passado terão alguma experiência em cooperação, que pode conduzir a uma maior propensão a cooperar (CARDAMONE e PUPO, 2015) e ao sucesso dos acordos cooperativos entre firmas e organizações de pesquisa (MORA-VALENTIN et al., 2004).

Vários estudos postulam que haveria um melhor resultado dos relacionamentos cooperativos se os parceiros tivessem tido experiências cooperativas prévias, tento no arcabouço de relacionamentos interorganizacionais em geral quanto naquele da cooperação entre firmas e organizações de pesquisa (MORA-VALENTIN et al., 2014). É interessante notar que, conforme os autores, um acordo colaborativo terá um maior nível de sucesso se as atividades envolvidas em relacionamentos cooperativos prévios estão relacionadas àquelas do acordo cooperativo atual, ou se houve algum tipo de colaboração positiva no passado entre os parceiros que cooperam no momento presente.

\section{Tipos de relacionamento}

Segundo a tabela 06, os modos de interação mais frequentes na interação U-E entre PMEs brasileiras e GPs, que partem destes últimos para o setor produtivo, são pesquisa científica com uso imediato dos resultados (podendo-se considerar como pesquisa de curto prazo), com 27,9\% do total dos relacionamentos, transferência de tecnologia $(16,8 \%)$ e pesquisa científica sem uso imediato dos resultados (podendo-se considerar pesquisa de longo prazo) (12,8\%). Estes três tipos de relacionamento abarcam $57,5 \%$ do total. Por sua vez, entre os relacionamentos que partem do setor produtivo para os GPs, embora em menor magnitude, os mais frequentes foram insumos materiais (9,9\%) e transferência de tecnologia (2,2\%). Estes dados indicam que as colaborações entre os GPs e o setor produtivo, conforme

\footnotetext{
${ }^{13}$ Albuquerque et al. (2005) confirmaram, a partir da PINTEC/IBGE 2000, a hipótese de que o envolvimento de uma firma com atividades de P\&D (interna e/ou externa) amplia a importância das universidades como fonte de informação para suas atividades inovativas. A realização de investimentos em P\&D amplia a capacidade de absorção de conhecimentos da firma e, por essa razão, elas tendem a valorizar mais as universidades como fonte de informação. Ademais, ao identificarem que o conjunto das firmas que realizam apenas P\&D externo ocupa o segundo lugar na valorização das universidades, os autores sugeriram que é possível que essas firmas utilizem diretamente as universidades como fonte de seu P\&D (contratação de pesquisas), substituindo (pelo menos temporariamente) o P\&D interno. Para os autores, uma explicação para a existência de um número elevado de firmas sem atividades internas de $\mathrm{P} \& \mathrm{D}$ e que atribui importância alta e média para as universidades como fonte de informação pode ser a utilização de recursos da universidade como substitutos do investimento interno (possivelmente em decorrência da restrição de recursos financeiros passíveis de alocação para atividades contínuas ou não de P\&D). Outra hipótese seria a de que essas firmas, pelo relacionamento com as universidades, estariam em vias de iniciar atividades internas de P\&D.
} 
indicado pelos líderes, envolvem não apenas um fluxo unidirecional, mas também bidirecional de informação e conhecimento.

Suzigan et al. (2009) acrescentaram que apesar da preocupação com os resultados de curto prazo, que não é uma característica geral dos esforços de $\mathrm{P} \& \mathrm{D}$, a colaboração em pesquisa científica com uso imediato dos resultados envolve fluxos bidirecionais de interações entre a universidade e a indústria, por que normalmente ela absorve pesquisadores das unidades de $P \& D$ das firmas e pesquisadores da universidade. Desse modo, neste tipo de ligações, a interação entre a universidade e as firmas é um modo importante para a criação e difusão do conhecimento, dado que ela pode criar fluxos bidirecionais de informação e conhecimento.

A literatura salienta que, por sua natureza mais complexa, as interações bidirecionais tendem a envolver um intercâmbio mais intenso de informações e conhecimentos entre as partes e, dessa forma, trazer benefícios mais amplos para os agentes envolvidos, tanto do lado das firmas, como dos GPs acadêmicos. Arza e Vazquez (2010) ressaltam a importância do canal bidirecional para as firmas buscarem todos os tipos de benefícios - de inovação (longo prazo) e de produção (curto-prazo). Ainda segundo as autoras, o canal bidirecional produz benefícios de inovação para todas as firmas, independentemente se elas se encontram acima ou abaixo da firma média em termos de investimento em atividades inovativas in-house. Para as autoras, isso se verifica por que as firmas podem interagir com as organizações públicas de pesquisa através deste canal para substituir ou para complementar as atividades inovativas in-house.

Tabela 6

PMEs brasileiras interativas com grupos de pesquisa do Diretório de Grupos do CNPq, segundo tipos de relacionamento

\begin{tabular}{l|c|c}
\hline \multicolumn{1}{c|}{ Modos de interação de acordo com a origem } & Numero & $\%$ \\
\cline { 2 - 3 } Grupo de pesquisa $\rightarrow$ Setor produtivo & 482 & 12,8 \\
Pesquisa científica sem uso imediato & 1054 & 27,9 \\
Pesquisa científica com uso imediato & 166 & 4,4 \\
Eengenharia não-rotineira & 86 & 2,3 \\
Desenvolvimento de software & 635 & 16,8 \\
Transferência de tecnologia & 283 & 7,5 \\
Consultoria técnica & 31 & 0,8 \\
Insumos materiais & 206 & 5,5 \\
Treinamento de pessoal & 233 & 6,2 \\
Outros & & 1,9 \\
Setor produtivo $\rightarrow$ grupo de pesquisa & 70 & 1,1 \\
Engenharia não-rotineira & 40 & 2,2 \\
Desenvolvimento de software & 82 & 9,0 \\
Transferência de tecnologia & 339 & 1,9 \\
Insumos materiais & 71 & 100,0 \\
Treinamento de pessoal & 3778 & \\
\hline Total de relacionamentos & & \\
\hline
\end{tabular}

Nota: (a) inclusive o desenvolvimento de protótipo cabeça de série ou planta piloto para o parceiro

(b) inclusive o desenvolvimento fabricação de equipamentos para o grupo

Fonte: Elaboração própria a partir do DGP/CNPq e RAIS/MTE

\section{CONSIDERAÇÕES FINAIS}

Este trabalho apresenta alguns resultados preliminares e descritivos da base de dados do Censo 2010 do DGP/CNPq quanto às características estruturais de PMEs interativas com GPs do DGP/CNPq e de seus relacionamentos cooperativos.

Os resultados referentes às características estruturais das PMEs interativas com GPs de universidades e IPPs apontam um elevado grau de heterogeneidade estrutural das empresas interativas, 
um reflexo da heterogeneidade da estrutura produtiva brasileira e das empresas dessas faixas de porte em particular, já salientada por autores como Nogueira e Oliveira (2009) e Santos et al. (2012), entre outros.

Essa heterogeneidade é evidenciada, primeiramente, pela classificação das PMEs interativas de acordo com o nível de intensidade tecnológica setorial. Os dados do DGP permitem identificar que tanto empresas de setores de média e baixa intensidade tecnológica, quanto de setores com maiores oportunidades tecnológicas, como os setores “baseados na ciência e intensivos em P\&D” e os KIBs fazem uso da pesquisa pública no país. É importante salientar que estes resultados do DGP/CNPq sublinham uma particularidade em relação à literatura internacional (KLEVORICK et al., 1995; COHEN et al, 2002, entre outros), que aponta a importância da interação U-E argumentado que as indústrias baseadas em ciência dependem fortemente do progresso na ciência e na tecnologia.

Adicionalmente, as informações referentes ao número de empregados com ensino superior ou mais das PMEs interativas sugerem que são bastante heterogêneos os seus esforços em P\&D. A elevada participação de empresas com escassos recursos internos, evidenciada pela baixa (ou ainda pela ausência de) capacidade de absorção potencial e realizada, pode sugerir que tais empresas necessitem do conhecimento externo de universidades e IPPs em sua dinâmica, como forma de superar a lacuna de recursos internos. Esse argumento é corroborado pela PINTEC/IBGE, na qual parcela significativa de PMEs aponta a falta de pessoal qualificado (entre outros recursos internos) como um problema e obstáculo à inovação.

Conforme o DGP/CNPq, o conhecimento de universidades e IPPs é transferido dos GPs para as PMEs tanto por meio da pesquisa científica com uso imediato dos resultados e da transferência de tecnologia, que podem ser caraterizados como relacionamentos de curto prazo, quanto da pesquisa científica sem uso imediato dos resultados (um relacionamento de longo prazo). Esses dados indicam que as colaborações entre os GPs e o setor produtivo envolvem não apenas um fluxo unidirecional, mas também bidirecional de informação e conhecimento. Dessa forma, a universidade brasileira pode desempenhar um importante papel em um ambiente com recursos mais limitados, não somente pela prestação de serviços às PMEs, que é um modo de se transferir conhecimento codificado, mas também pelo estabelecimento da pesquisa cooperativa, na qual o conhecimento envolvido é mais tácito e requer uma interação estreita entre a universidade e as firmas (SUZIGAN et al., 2009). Ademais, a elevada a existência de vínculos prévios entre as partes pode ser um indicativo da maior propensão a cooperar destas empresas.

Os resultados acima sugerem que a interação U-E pode constituir uma relação importante para o acesso das PMEs, em um ambiente com recursos mais limitados, a recursos fundamentais tais como informação, pessoal qualificado, serviços especializados, infraestrutura laboratorial, etc.

Na perspectiva do exposto, os dados deste trabalho evidenciam que há um importante papel desempenhado pela universidade e pela pesquisa acadêmica na criação e difusão de novos conhecimentos entre as PMEs brasileiras. Tais resultados trazem novas evidências ao argumento de Albuquerque et al. (2005), Suzigan et al. (2009) e Rapini et al. (2009) de que, em contraste ao papel da pesquisa acadêmica em países desenvolvidos, em países em desenvolvimento a universidade poderia ter diferente características e distintos padrões de interações com firmas. Ou seja, em NSIs imaturos as universidades podem substituir e complementar os investimentos em P\&D relativamente mais fracos das firmas.

\section{REFERENCIAS}

ACS, Z.; AUDRETSCH, D.; FELDMAN, M. R\&D Spillovers and Innovative Activity. Managerial and Decision Economics, vol.. 15, 131-138, 1994a.

ACS, Z.; AUDRETSCH, D.; FELDMAN, M. R \&D Spillovers and Recipient Firm Size. The Review of Economics and Statistics, Vol. 76, No. 2, pp. 336-340, 1994b.

AUDRETSCH, D.; VIVARELLI, M. Small firms and R\&D spillovers: evidence from Italy. Revue d'Economie Industrielle 67(1): 225-237, 1994.

ALBUQUERQUE, E. National systems of innovation and non-OCED countries: notes about a rudimentary and tentative "tipology”. Brazilian Journal of Political Economy, vol. 19, n. 4 (76), octobernovember, p. 35-52, 1999. 
ALBUQURQUE, E. SILVA, L.; POVOA, L. Diferenciação intersetorial na interação entre empresas e universidades no Brasil. São Paulo em Perspectiva, v. 19, n. 1, p. 95-104, jan./mar. 2005.

ARZA, V.; VAZQUEZ, C. Interactions between public research organisations and industry in Argentina. Science and Public Policy, 37(7), p. 499-511, August 2010.

BRUNEEL, J.; D'ESTE, P.; SALTER, A. Investigating the factors that diminish the barriers to university-industry collaboration. Research Policy, v. 39, p. 858-868, 2010.

CALLIARI, T.; RAPINI, M. Um estudo sobre os determinantes da distância geográfica nas interações universidade- empresa. In: XVI Seminário sobre a Economia Mineira. Diamantina: CEDEPLAR, 2014.

CAMPOS, B., URRACA RUIZ, A. Padrões Setoriais de Inovação na Indústria Brasileira. Revista Brasileira de Inovação, v.8, n1, p.167-210, 2009.

CARDAMONE, P.; PUPO, V. R\&D cooperation between firms and universities: some evidence in five European countries. Working Papr n. 01-15. Università Della Calabria, $2015 .$.

COHEN, W.; LEVINTHAL, D. Absorptive capacity: a new perspective on learning and innovation. Administrative Science Quarterly 35(1) pp 128-152, 1990.

COHEN, W.; NELSON, R.; WALSH, J. Links and impacts: the influence of public research on industrial R\&D. Management Science, vol. 48, n.1, jan. p, 1-23, 2002.

DE FUENTES, C.; DUTRENIT, G. Best channels of academia-industry interaction for long-term benefit. Research Policy, 41 (9), p. 1666-1682, 2012.

FERNANDES, A. C.; SOUZA, B.; SILVA, A.; SUZIGAN, W.; CHAVES, C. ALBUQUERQUE, E. Academy-industry links in Brazil: evidence about channels and benefits for firms and researchers. Science and Public Policy, 37, p. 485-498, 2010.

FONTANA, R.; GEUNA, A.; MATT, M. 2003. Firm size and openness: the driving forces of universityindustry collaboration. SPRU Working Paper Series, n.103, Science and Technology Policy Research, University of Sussex, 2003.

FREEL, M. Barriers to product innovation in small manufacturing firms. International Small Business Journal, 18 (2), pp. 60-80, 2000.

FREIRE, C. E.. Um estudo sobre os serviços intensivos em conhecimento no Brasil. In: DE NEGRI, J. A.; KUBOTA, L. C. (Org). Estrutura e dinâmica do setor de serviços no Brasil. Brasília: Ipea, 2006.

GARCIA, R.; ARAUJO, V. C.; MASCARINI, S.; SANTOS, E. G. Efeitos da qualidade da pesquisa acadêmica sobre a distância geográfica das interações universidade-empresa. Estudos Econômicos, v. 44, n. 1, p. 105-132, 2014.

HANEL, P.; ST-PIERRE, M. Industry-university collaborations by Canadian manufacturing firms. Journal of Technology Transfer, 31, p. 485-499.

HEWITT-DUNDAS, N. Resource and capability constraints to innovation in small and large plants. Small Business Economics, 26 (3), pp. 257-277, 2006.

HIPP, C.; GRUPP, H. Innovation in the service sector: The demand for service-specific innovation measurement concepts and typologies. Research Policy, 34, p. 517-535, 2005.

KLEVORICK, A.; LEVIN, R.; NELSON, R.; WINTER, S. On the sources and significance of inter-industry differences in technological opportunities. Research Policy, n. 24, p. 185-205, 1995

KUBOTA, L. C. As Kibs e a inovação tecnológica das firmas de serviços. Economia e Sociedade, v. 18, n. 2 (36), p. 349-369, ago. 2009.

LAURSEN, K.; SALTER, A. Searching high and low: what types of firms use universities as a source of innovation? Research Policy, 33 (8), p. 1201-1215, 2004.

LAURSEN, K.; REICHSTEIN, T.; SALTERS, A. Exploring the effect of Geographical Proximity and University Quality on University-Industry Collaboration in the United Kingdom. Regional Studies 45(4), p. 507-523, 2011.

LINK, A.L.; REES, J. Firm Size, University Based Research and the Returns to R\&D. Small Business Economics. Vol. 2: 25-31., 1990. 
METCALFE, J. S. Equilibrium and evolutionary foundations of competition and technology policy: new perspectives on the division of labour and the innovation process. Revista Brasileira de Inovação, vol.2, n.1, pp. 111-146, 2003.

MILES, I. Research and development (R\&D) beyond manufacturing: the strange case of services R\&D. R\&D Management, v. 37, n. 3, p. 249-268, 2007.

MOHNEN, P.; HOAREAU, C. What type of enterprise forges close links with universities and government labs? Evidence from CIS 2. Managerial and Decision Economics, 24 (2-3), p. 133-145, 2003

MORA-VALENTIN, E M..; MONTORO-SANCHEZ, A.; GUERRAS-MARTIN, L. A. Determining factors in the success of R\&D cooperative agreements between firms and research organizations. Research Policy, 33 (1), p. 17-40, 2004.

NELSON, R.; ROSENBERG, N. Technical innovation and national systems In: NELSON, R. (Ed.) National Innovation Systems: a comparative analysis. New York, Oxford: Oxford University Press, pp. 321, 1993.

NOGUEIRA, M.; OLIVEIRA, J. M. Da baleia ao ornitorrinco: contribuições para a compreensão do universo das micro e pequenas empresas brasileiras. In: Radar: tecnologia, produção e comércio exterior. Brasília: IPEA, n. 1, pp. 7-18, abril, 2009.

NOTEBOOM, B. Innovation and diffusion in small firms: theory and evidence. Small Business Economics, 6 (5) pp.327-347, 1994.OECD Science, Technology and Industry Scoreboard 2009. OECD Publishing.

PINHO, M. A visão das empresas sobre as relações entre universidade e empresa no Brasil: uma análise baseada nas categorias de intensidade tecnológica. Revista de Economia, v. 37, n. especial, p. 279-306, 2011.OECD (2009)

POVOA, L.; MONSUETO, S. E. Tamanho das empresas, interação com universidades e inovação. Revista de Economia, v. 37, n. ${ }^{\circ}$ especial, ano 35, p. 10-22, 2011.

RAPINI. M. Interação Universidade-Empresa no Brasil: evidências do Diretório dos Grupos de Pesquisa no Brasil. Estudos Econômicos, 37 (2), p. 212-233, 2007.

RAPINI, M.; ALBUQUERQUE, E; CHAVES, C.; SILVA, L.; SOUZA, S.; RIGHI, H.; CRUZ, W. University-industry interactions in an immature system of innovation: evidence from Minas Gerais, Brazil. Science and Public Policy, 36 (5), p. 373-386, June 2009.

RAPINI, M.; OLIVEIRA, V..; CALIARI, T. Como a interação universidade-empresa é remunerada no brasil: evidências dos grupos de pesquisa do CNPq. Texto para Discussão $\mathrm{N}^{\circ}$ 513. Belo Horizonte: CEDEPLAR/UFMG, 2015.

RIGHI, H.; RAPINI, M. Metodologia e apresentação da Base de Dados do Censo 2004 do Diretório dos Grupos de Pesquisa do Conselho Nacional de Pesquisa Científica e Tecnológica (CNPq). In: SUZIGAN, W.; ALBUQUERQUE, E.; CARIO, S. (Orgs) Em busca da inovação: interação universidade-empresa no Brasil. Belo Horizonte: Editora Autêntica, 2011, p. 45-73.

ROTHWELL, R. Small firms, innovation and industrial change. Small Business Economics, 1 (1), pp 5164, 1989.

SANTOS, A. L.; KREIN, J. D.; CALIXTRE, A. (Orgs) Micro e pequenas empresas: mercado de trabalho e implicação para o desenvolvimento. Rio de Janeiro: Ipea, 2012.

SANTORO, M.; CHAKRABARTI, A. Firm size and technology centrality in industry-university interactions. Research Policy, 31, p.1163-1180, 2002.

SCHARTINGER, D.; SHIBANY, A.; GASSLER, H. Interactive relations between universities and firms: empirical evidence for Austria. Journal of Technology Transfer, v.26, pp.255-268, 2001.

SCHARTINGER, D.; RAMMER, C.; FISCHER, M.; FRÖHLICH, J. Knowledge interactions between universities and industry in Austria: sectoral patterns and determinants. Research Policy, 31, 303-328, 2002. 
SUZIGAN, W.; ALBUQUERQUE, E.; GARCIA, R.; RAPINI, M. University and industry linkages in Brazil: some preliminary and descriptive results. Seoul Journal of Economics, 22(4), p. 591-691, 2009.

TEIXEIRA, A. L.; ROSA, A.; RUFFONI, J.; RAPINI, M. Dimensões da capacidade de absorção, qualificação da mão de obra, P\&D e desempenho inovativo. Revista Brasileira de Inovação, 15, (1), p. 139-164, jan/jun. 2016. 